\title{
Microbiology of secondary infections in Buruli ulcer lesions; implications for therapeutic interventions
}

\author{
Elizabeth Gyamfi ${ }^{1,2,3}$, Charles A Narh ${ }^{4,5}$, Charles Quaye ${ }^{4}$, Adiza Abbass ${ }^{2,3}$, Bartholomew Dzudzor ${ }^{1}$ and \\ Lydia Mosi ${ }^{2,3^{*}}$ (D)
}

\begin{abstract}
Background: Buruli ulcer (BU) is a skin disease caused by Mycobacterium ulcerans and is the second most common mycobacterial disease after tuberculosis in Ghana and Côte d'Ivoire. M. ulcerans produces mycolactone, an immunosuppressant macrolide toxin, responsible for the characteristic painless nature of the infection. Secondary infection of ulcers before, during and after treatment has been associated with delayed wound healing and resistance to streptomycin and rifampicin. However, not much is known of the bacteria causing these infections as well as antimicrobial drugs for treating the secondary microorganism. This study sought to identify secondary microbial infections in BU lesions and to determine their levels of antibiotic resistance due to the prolonged antibiotic therapy required for Buruli ulcer.

Results: Swabs from fifty-one suspected BU cases were sampled in the Amansie Central District from St. Peters Hospital (Jacobu) and through an active case surveillance. Forty of the samples were M. ulcerans (BU) positive. Secondary bacteria were identified in all sampled lesions $(N=51)$. The predominant bacteria identified in both BU and Non-BU groups were Staphylococci spp and Bacilli spp. The most diverse secondary bacteria were detected among BU patients who were not yet on antibiotic treatment. Fungal species identified were Candida spp, Penicillium spp and Trichodema spp. Selected secondary bacteria isolates were all susceptible to clarithromycin and amikacin among both BU and Non-BU patients. Majority, however, had high resistance to streptomycin.

Conclusions: Microorganisms other than M. ulcerans colonize and proliferate on BU lesions. Secondary microorganisms of BU wounds were mainly Staphylococcus spp, Bacillus spp and Pseudomonas spp. These secondary microorganisms were less predominant in BU patients under treatment compared to those without treatment. The delay in healing that are experienced by some BU patients could be as a result of these bacteria and fungi colonizing and proliferating in BU lesions. Clarithromycin and amikacin are likely suitable drugs for clearance of secondary infection of Buruli ulcer.
\end{abstract}

Keywords: Mycobacterium ulcerans, Buruli ulcer, Secondary Infection, Antimicrobial resistance, Antibiotics

\footnotetext{
* Correspondence: Imosi@ug.edu.gh

2Department of Biochemistry, Cell and Molecular Biology, University of

Ghana, Legon, Accra, Ghana

${ }^{3}$ West African Center for Cell Biology of Infectious Pathogens, University of

Ghana, Legon, Accra, Ghana

Full list of author information is available at the end of the article
}

(c) The Author(s). 2021 Open Access This article is licensed under a Creative Commons Attribution 4.0 International License, which permits use, sharing, adaptation, distribution and reproduction in any medium or format, as long as you give appropriate credit to the original author(s) and the source, provide a link to the Creative Commons licence, and indicate if changes were made. The images or other third party material in this article are included in the article's Creative Commons licence, unless indicated otherwise in a credit line to the material. If material is not included in the article's Creative Commons licence and your intended use is not permitted by statutory regulation or exceeds the permitted use, you will need to obtain permission directly from the copyright holder. To view a copy of this licence, visit http://creativecommons.org/licenses/by/4.0/. The Creative Commons Public Domain Dedication waiver (http://creativecommons.org/publicdomain/zero/1.0/) applies to the data made available in this article, unless otherwise stated in a credit line to the data. 


\section{Background}

Buruli ulcer (BU) is a necrotizing skin disease caused by Mycobacterium ulcerans (MU). It is characterized by a painless nodule, papule, plaque or edema, which can develop into a painless ulcer with undermined edges, often leading to overturning sequelae and in rare cases, osteomyelitis [1]. The exact mode of transmission of the disease remains unclear. Globally, it is the third most common disease caused by mycobacteria after tuberculosis and leprosy [2]. Buruli ulcer remains a public health problem in Ghana; particularly, in the Amansie West and Central Districts [3].

The pathology of MU is different from other mycobacterial pathogens; it is primarily extracellular and harbors a plasmid which encodes mycolactone; a polyketidederived macrolide toxin [4]. Cellular activities of mycolactone accounts for majority of the pathogenesis related to the disease. It also suppresses the host's immune features from eliciting inflammatory responses [5], which explains why the majority of BU patients feel no pain. Pain experienced by BU patients have been associated with wound dressing and physiotherapy [6, 7] and underlying secondary infection [8] which is enhanced by the toxins ability to disrupt protective barriers of the skin [9]. Both pathogenic and opportunistic microbes, stemming from normal skin flora or the immediate environment, could colonize skin ulcers and cause secondary microbial infections among BU patients [10, 11].

Even though MU can infect any part of the body, lesions predominantly localize on the extremities (especially the lower limbs) due to the comparatively cooler temperature which favors the limited optimum growth of $\mathrm{MU}$ at $32^{\circ} \mathrm{C}$. This may also be the result of these parts frequently being in contact with microbial contaminated environments and thereby, increasing the risk of bacterial infection of BU wounds [12]. The cytotoxic effect of mycolactone including destruction of skin and subcutaneous fat may provide fertile grounds for the colonization and proliferation of microorganisms from normal skin flora and pathogenic species from the environment which may result delayed in wound healing.

Even though mycolactone was initially thought to inhibit the growth of other bacteria on BU lesions, recent reports have identified secondary bacterial infections of BU wounds in both pre-treatment, during treatment, and post treatment $[10,13,14]$. Few studies have highlighted fungal element associated with BU [15]. There is, albeit insufficient information on the effect of antibiotics on secondary microorganism present in BU wounds. Microbial infections generally, have insignificant influence on rapidly healing wounds but may create large colonies on slow healing wounds [16]. Many wound and skin infections that complicate skin lesions are caused by mixed bacterial flora where they survive synergistically [17]. Interestingly, wound colonization by yeasts and fungi occasionally occur after treatment has usually begun [18]. There is also a paucity of information on the effect of the recommended antibiotics for BU treatment on secondary microorganism present in BU lesions [19].

$\mathrm{BU}$ has been recognized as a health problem in Ghana and various researchers have investigated ways in which antibiotic treatment and wound management can be improved. Understanding the diversity and role of microbial secondary infections in BU lesions is crucial to improving treatment efficacy. This study focuses on microbiological and molecular based identification of secondary microbial organisms from suspected BU patients and their antimicrobial resistant phenotypes.

\section{Results}

Demographic information on study cohorts

Out of the 51 study participants $50.98 \%$ and $49.02 \%$ were females and males, respectively. Majority of the participant were adults with a total of 11 (21.6\%) being below the age of 18 years; 20 (39.2\%) participants were between 18 and 50 years and 20 (39.2\%) above 50 years. The youngest and oldest persons were males; with the youngest being a year old and the oldest being 80 years. Over $35 \%$ of respondents practiced farming and other agricultural activities as their main occupation (Fig. 1).

\section{Buruli ulcer case confirmation}

To confirm the presence of Mycobacterium ulcerans and hence, BU positive cases, all 51 samples were first screened for acid-fast bacilli using the acid-fast staining technique and amplification of the 16SrRNA gene specific for Mycobacteria spp. The samples positive for Mycobacteria were further screen for $M$. ulcerans by the amplification of IS2404. Microscopic detection of acid-fast rod-shaped bacteria was generally low and only $0.06 \%$ (3/ 51) of the samples were positive. Detection of Mycobacteria by amplification of the $16 \mathrm{~S}$ rRNA gene was high with $94.1 \%(48 / 51)$ of the samples testing positive. Based on the amplification of IS2404, 40 samples (78.4\%) were confirmed as $M$. ulcerans (BU) positive and 11 (21.6\%) were negative for $M$. ulcerans DNA (non-BU) (Fig. 2).

Out of the 40 positive cases, 14 (35\%) had already commenced BU antibiotic treatment (BT) with rifampicin and streptomycin and wound dressing before we began this study and 26 (65\%) had not (BNT). A total of $12.2 \%(5 / 40)$ of the BU participants on treatment had undergone surgery associated with Buruli ulcer. Based on lesion category, as directed by WHO BU guidelines[20], 22.5\% (9/40) were category I (> $5 \mathrm{~cm}$ in width), $40 \%(16 / 40)$ were category II $(\leq 5 \mathrm{~cm}-15 \mathrm{~cm})$ whilst $37.5 \%(15 / 40)$ were category III (> $15 \mathrm{~cm}$ ) lesion (Fig. 3).

A higher percentage of $\mathrm{BU}$ patients under treatment were in category I compared to category II and III. A 


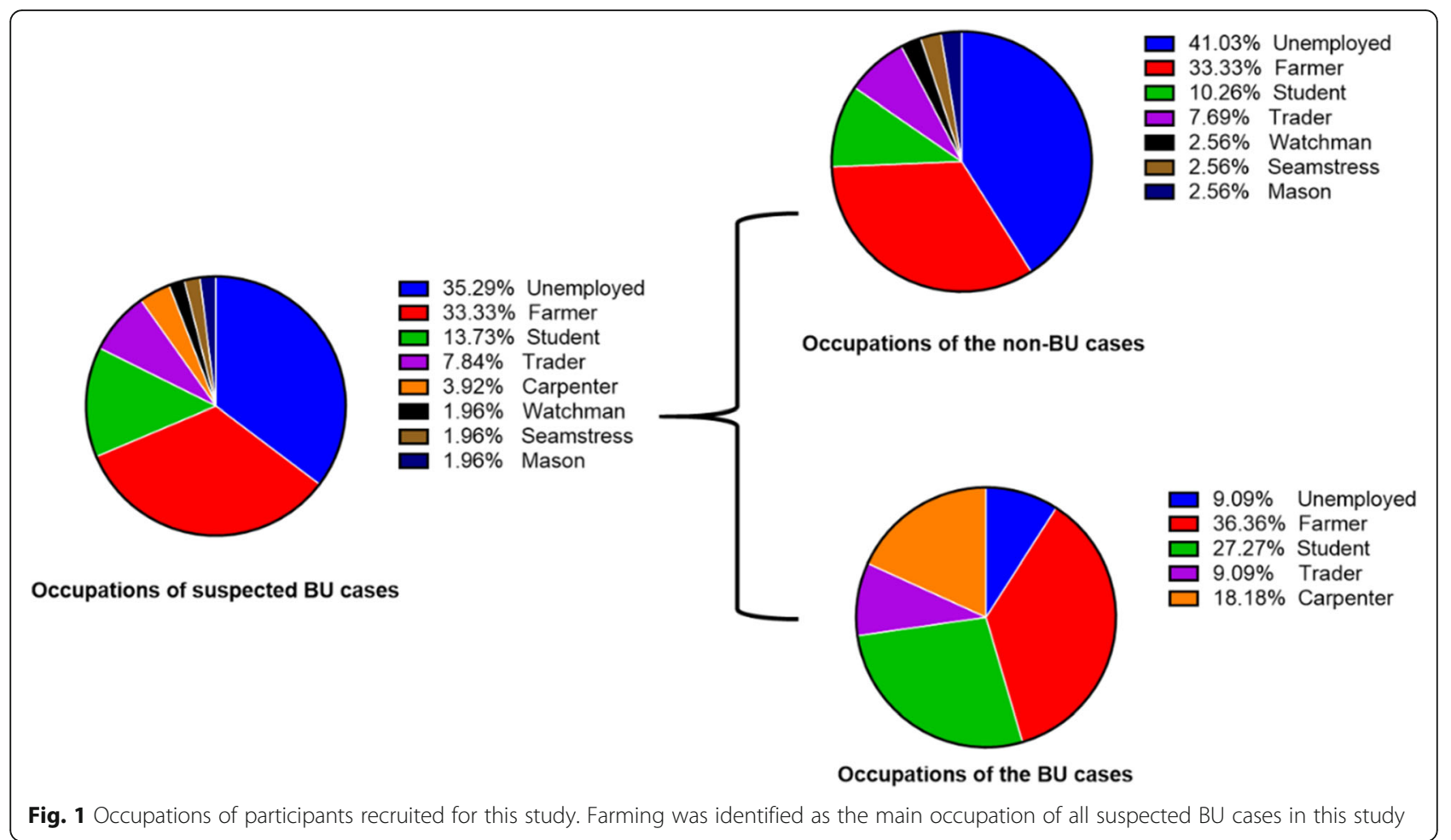

significant difference was observed between treatment of BU and category of lesions (chi-square test of association; df 2, $p=0.004$ ). Therefore, BU patients who sought the recommended treatment for Buruli ulcer at an early stage were less likely to migrate from category I (Fig. 3).

\section{Characteristics of isolated secondary microorganisms from BU wounds}

Plate cultures were performed for all 51 samples to isolate microorganisms present in the lesions. All the LB agar plates ( $N=51$ : $40 \mathrm{BU}$ and 11 non-BU samples) had bacterial growth. Of the $40 \mathrm{BU}$ positive samples cultured on mannitol salt agar, growth was observed on 33 (83\%) of the plates, indicating the presence of either Staphylococci or Micrococci spp in the lesions. Out of these, 32/ 33 (97\%) were mannitol fermenters (pathogenic species) whilst 1/33 (3\%) was a non-mannitol fermenter (nonpathogenic species). Mannitol fermenters were observed on 22/26 (84.6\%) of BNT group and 11/14 (78.6\%) of the $\mathrm{BT}$ group. For the BU negative samples, mannitol fermenters (pathogenic species) were observed on 7/11 (63.6\%) whiles non-mannitol fermenters were observed on $1 / 11$

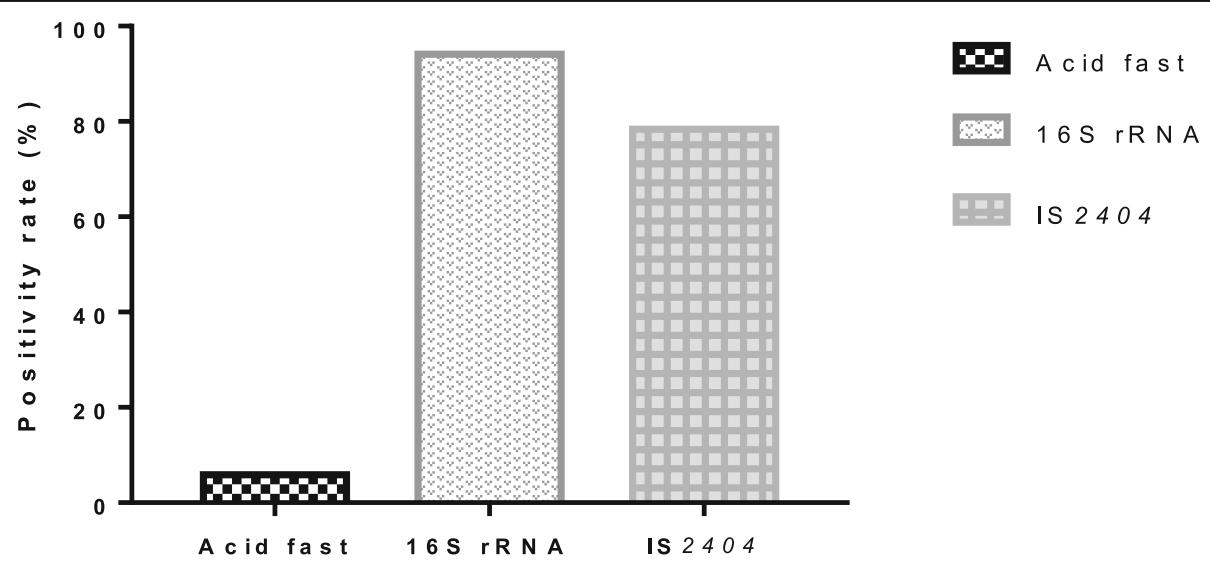

Fig. 2 Acid-fast and PCR positivity among the suspected BU cases. All patient lesion samples were screened for the presence of acid-fast bacteria, mycobacterial 16SrRNA and IS2404 gene amplification for BU case confirmation. A higher positivity rate was observed for PCR (16SrRNA \& IS2404) compared to direct smear microscopy (detection of acid-fast bacilli) for the confirmation of BU cases 


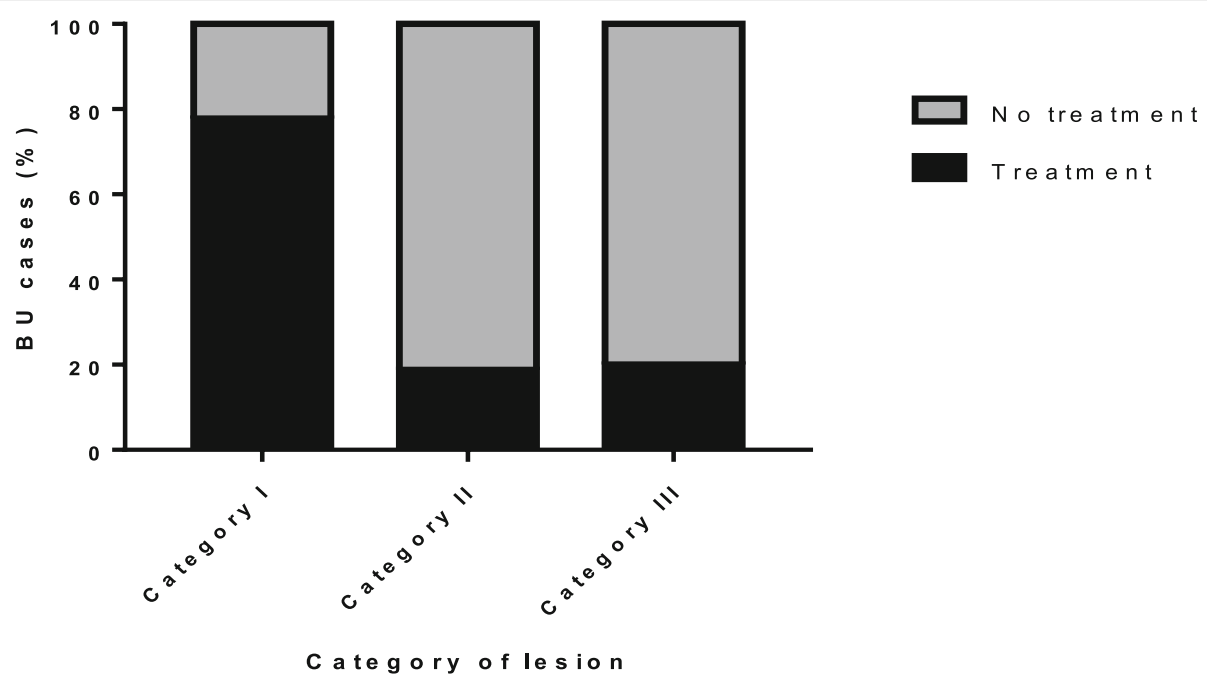

Fig. 3 Category of BU lesions with or without treatment. Rifampicin and streptomycin were used at the health centres for BU treatment. A higher percentage of untreated BU patients were in category II and category III compared with category I

(9\%). A mixed infection (both mannitol and non-mannitol fermenters) was observed on 1 plate (Fig. 4).

Of the forty (40) BU positive samples cultured on MacConkey agar, growth was observed on 37 (93\%) of the plates, indicating the presence of either gram negative or enteric bacteria. All the 37/40 (93\%) had growth of lactose fermenters while 17/37 (43\%) had growth of non-lactose fermenters. These results indicate the presence of mixed and/or multiple infections (both lactose and non-lactose fermenters) on some of the wounds (45.9\%\%). All the BNT samples 26/26 (100\%) had the growth of lactose fermenters whiles BT samples had 11/ 24 (78.6\%). For the non-lactone fermenters observed, growth was observed in $14 / 26(53.8 \%)$ of the BNT samples and 3/14 (21.4\%) of the BT samples. These results indicate the presence of mixed and/or multiple infections (both lactose and non-lactose fermenters) in some of the lesions (45.9\%\%). For the BU negative samples, lactose fermenters were observed on all 11 samples (100\%). Non-lactose fermenters were observed on $5 / 11$ (45.4\%) plates, indicating the presence of mixed infection (both lactose and non-lactose fermenters) in 5/11 (45.4\%) of the samples (Fig. 4).

To detect fungal species, the samples $(N=40 \mathrm{BU}$ positive samples) were cultured on Sabouraud dextrose agar. Growth of fungal elements was observed on 25/40 $(62.5 \%)$ plates. Out of these, 23/35 (92\%) were identified as yeast whiles $8 / 25(32 \% \%)$ were mold. Mixed infections of both yeast and mold were observed in 6/25 (24\%) of the agar plates. Of the total number of yeasts observed, 13/26 (50\%) were samples from the BNT group whiles $10 / 14(71.4 \%)$ were samples from the BT group. For the

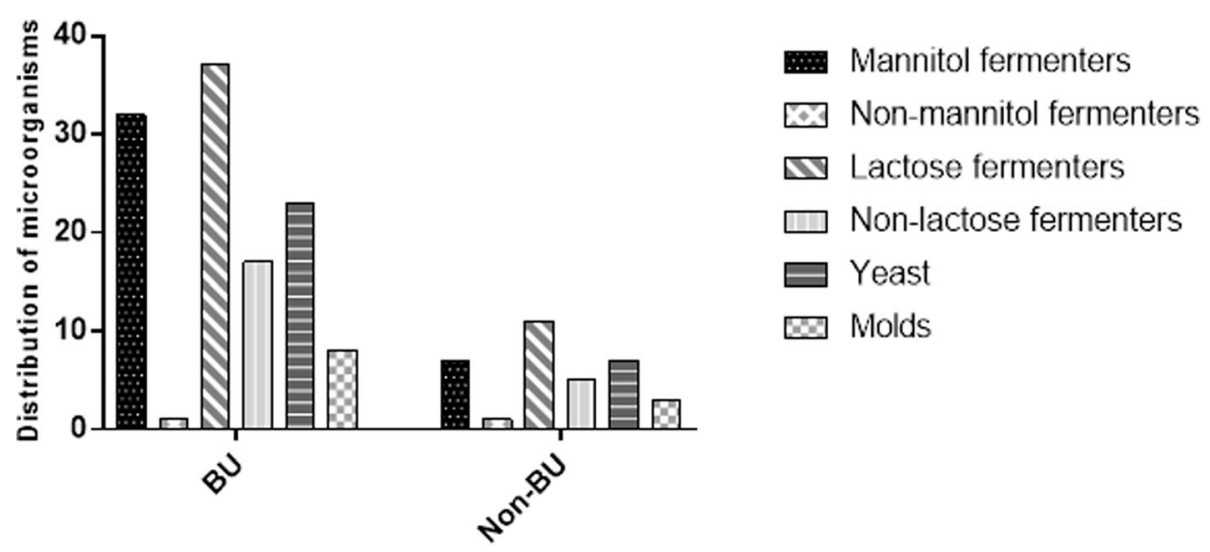

Fig. 4 Secondary microbes identified through culture dependent methods. Data is representative of the total number of microbial isolates recovered from each participant's (both BU positive lesions and Non-BU lesions) sample after culturing on Sabouraud dextrose agar, Mannitol agar and Mac Conkey 
molds observed, $5 / 26$ (19.2\%) were from the BNT group and $3 / 14(21.4 \%)$ were samples from the BT group. Of the BU negative samples $(N=11)$, growth was observed on $9(81.8 \%)$ out of the 11 agar plates. Out of these, $7 / 9$ (71.7\%) were identified as yeast and 3/9 (33.3\%) were mold. Thus $2 / 9$ (22.2\%) of the BU negative lesions had a mixed infection of both yeast and molds (Fig. 4).

Culture on M7H10 agar was maintained for 6 months as recommended [21]. Only 3 of the 51 decontaminated samples cultured on the M7H10 plates had visible characteristics of mycobacteria growth (rough and dry colonies). Further characterization of the colonies using microscopy revealed that 2 were non-acid fast clubshaped bacteria and the other was found to be acid fast coccoid shaped bacteria.

\section{Molecular identification of microbial isolates}

Further characterization of the DNA obtained from the isolated bacteria was achieved using PCR amplification of the universal bacterial 16SrRNA gene (Table 1), followed by amplicon sequencing to identify the microorganisms. Majority of the bacteria identified were Staphylococcus spp (24\%), Bacillus spp (30\%), Pseudomonas spp (6\%) and Alcaligenes spp (6\%). Other bacteria identified include Proteus spp, Aeromonas spp, Enterobacter spp, Providencia spp, Klebsiella spp among others. More bacteria diversity was observed among BU patients who were not yet on treatment (Fig. 5). PCR amplification followed by sequencing of the ITS region of the isolated fungi detected the presence of only 4 fungal species; Penicillium citrinum, Trichodema longibrachiatum, Candida parapsilosis and Candida duobushaemulonii.

PCR positive amplicons for the $16 \mathrm{~S}$ hyper-viable region of mycobacteria were detected as Corynebacterium spp (80.4\%); mainly C. diphtheriae, including others such as C. aurimucosum, C. striatum, C. pollutisoli and $C$. jeikeium, Brevibacterium spp. JT-1 (6.6\%), M. marinum (6.6\%) and M. ulcerans (6.6\%) after blasting on NCBI. Majority (60\%) were identified on BU patients who had not begun the recommended antibiotic treatment with the rest distributed among $\mathrm{BU}$ patients under treatment (27\%) as well as the non- BU groups (13\%).

\section{Antimicrobial sensitivity profiles}

Clarithromycin $(30 \mu \mathrm{g})$, kanamycin $(30 \mu \mathrm{g})$, hygromycin B $(30 \mu \mathrm{g})$, streptomycin $(10 \mu \mathrm{g})$, amikacin $(30 \mu \mathrm{g})$ and rifampicin $(5 \mu \mathrm{g})$ are drugs known for treatment of $\mathrm{BU}$ and to suppress mycobacterial growth in in-vitro experiments. These drugs were tested against the isolated bacteria to determine their efficacy against the secondary bacteria recovered from the BU wounds. All the bacteria isolated in this study were susceptible to clarithromycin and amikacin (100\%). This was followed by hygromycin B with $88.9 \%$ susceptibility and $11.1 \%$ intermediate. No bacterium was resistant to hygromycin B. Susceptibility to rifampicin which is recommended for BU treatment was similar to that of hygromycin B (82.2\%) with resistance observed in $17.8 \%$ of the bacterial isolates. There were no intermediate zones observed. Kanamycin showed an average susceptibility of $51.1 \%$ and $48.9 \%$ intermediate zones. Streptomycin responded poorly as an antibiotic for treatment of secondary microbial infections. None of the bacteria were susceptible to streptomycin. However, intermediate zones were observed in $68.9 \%$ of the bacterial isolates and resistance in $17.8 \%$ of the bacteria isolates (Fig. 6). Resistance was mainly observed among the Bacillus spp, Alcaligenes spp and some Staphylococci spp. Generally, resistance to streptomycin and rifampicin was observed in both BNT and BT group. However, resistance was found to be higher among the BT group (60\% for streptomycin, $20 \%$ for rifampicin) compared to the BNT group (33\% for streptomycin, $17 \%$ for rifampicin). Nevertheless, bacteria isolated from the BT group were all susceptible to clarithromycin, hygromycin B and Amikacin whilst that for the BNT were susceptible to only clarithromycin and amikacin.

\section{Discussion}

Characterization of microorganisms causing secondary infections in Buruli ulcer patients is necessary to understand

Table 1 List of Primers used for PCR Amplification

\begin{tabular}{|c|c|c|c|}
\hline Primers & Forward and reverse sequences $\left(5^{\prime}-3^{\prime}\right)$ & Expected sizes (bp) & References \\
\hline 1_16SF & $\begin{array}{l}\text { F-AGGAGGTGATCCAACCGCA } \\
\text { R-AACTGGAGGAAGGTGGGAT }\end{array}$ & 350 & [22] \\
\hline 16SrRNA & $\begin{array}{l}\text { MSHA-AAAAAGCGACAAACCTACGAG } \\
\text { PA-AGAGTITGATCCTGGCTCAG }\end{array}$ & 620 & [23] \\
\hline IS2404 (nested 1) & $\begin{array}{l}\text { pGp1: AGGGCAGCGCGGTGATACGG } \\
\text { pGp2: CAGTGGATTGGTGCCGATCGAG }\end{array}$ & 400 & {$[24,25]$} \\
\hline IS2404 (nested 2) & $\begin{array}{l}\text { pGp3: GGCGCAGATCAACTCGCGGT } \\
\text { pGp4: CTGCGTGGTGCTITACGCGC }\end{array}$ & 200 & {$[24,25]$} \\
\hline ITS & $\begin{array}{l}\text { ITS1-TCCGTAGGTGAACCTGCGG } \\
\text { ITS4-TCCTCCGCTTATTGATATGC }\end{array}$ & variable & [26] \\
\hline
\end{tabular}




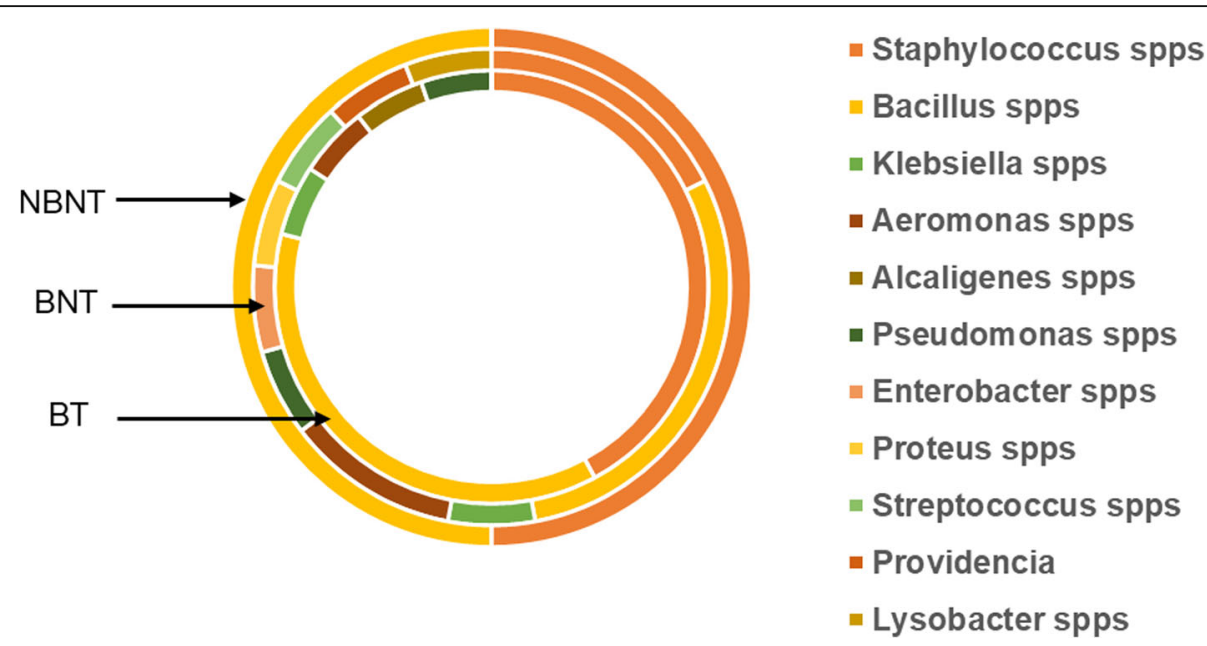

Fig. 5 Bacteria species identified after amplicon sequencing. PCR amplicons for universal bacteria 16SrRNA were sequenced using the sanger method and queried using BLASTn for comparative sequence homology to identify bacteria present in the lesions. The outer circle represents bacteria identified from BU negative study group (NBNT), the middle circle represents BU patients that were not on treatment (BNT) and the inner circle represents the BU study group on the recommended antibiotic treatment (BT)

their role in BU treatment efficacy and M. ulcerans pathogenesis. This information is also important in the holistic treatment and management of the disease. Although risk factors for bacteria colonization on BU lesions have not been extensively investigated, delayed treatment and insufficient wound assessment might contribute to the colonization and may prolong wound healing [27]. This study thus aimed at identifying secondary contaminating microorganism that may colonize BU wounds. This study also supported the assertion from other studies that other microbes, other than M. ulcerans can colonize BU wounds [11, 13, 28].

In comparison with PCR, we showed that acid-fast microscopy had a lower sensitivity in detecting MU (Fig. 2), which is consistent with similar observations in other studies [29]. This is partly due to the uneven distribution of $M$. ulcerans within the lesion and inability of the lesion swabbing technique to obtain a high enough bacterial load for visualization under a microscope. Additionally, majority of the patients enrolled in this study had already commenced antibiotic therapy and or wound dressing, therefore $M$. ulcerans loads and other secondary microorganisms could have been cleared from the lesions at the time of sampling. Moreover, some lesions with BU-like clinical presentation could have been misdiagnosed based on just the appearance of the lesion. Thus, detection of the insertion sequence 2404 which has a high sensitivity and specificity rate for $\mathrm{BU}$ case identification was used as cut-off for distinguishing BU verses non-BU cases.

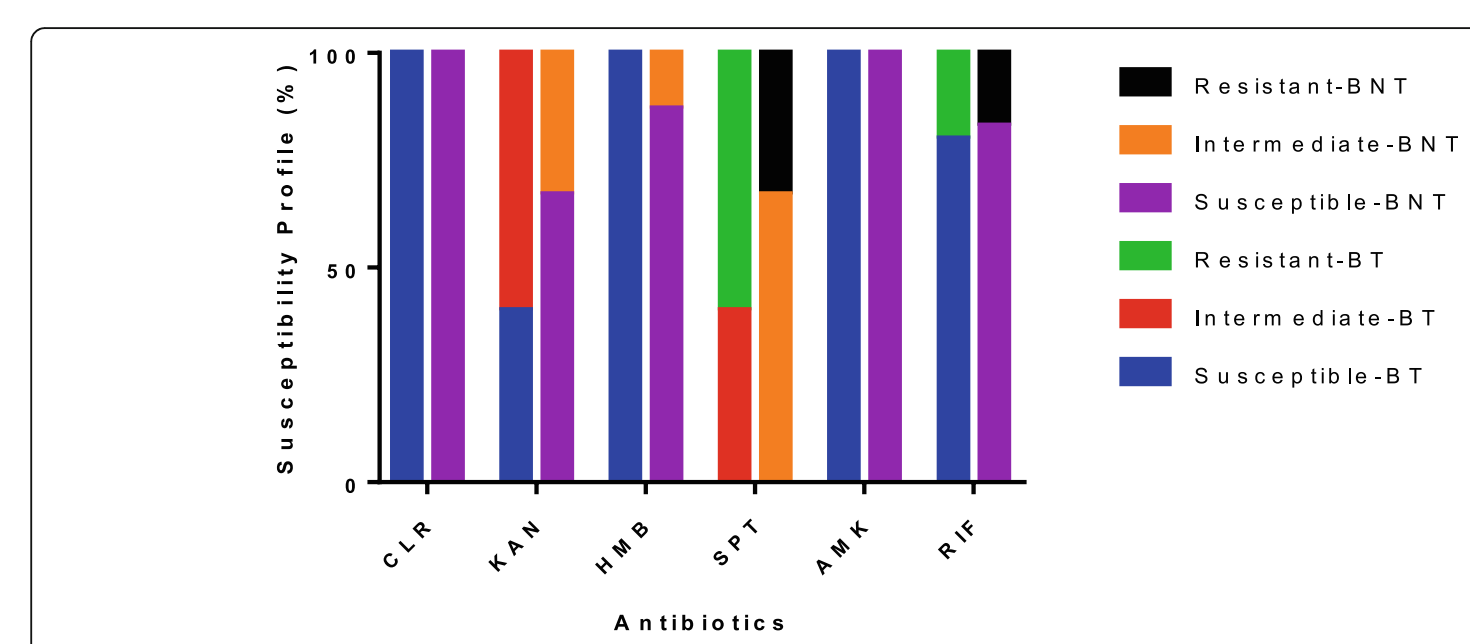

Fig. 6 Efficacy of selected antibiotics against secondary bacteria that infect BU lesions. Clarithromycin (CLR), kanamycin (KAN), hygromycin B (HMB), streptomycin (STR), amikacin (AMK) and rifampicin (RIF) were tested against the recovered secondary bacterial isolates. The susceptibility profiles are shown for bacteria recovered from both patients who had commenced treatment (BT) and those who were not on treatment (BNT) 
The amplification of IS2404 discriminated mycolactone producing mycobacteria (MPM) from nontuberculous mycobacteria (NTM), which is characterized by the detection of $16 \mathrm{~S}$ rRNA hypervariable region. 16SrRNA positivity for mycobacteria was higher compared to IS2404 positivity as expected $[29,30]$ and the 59 noncoding promoter region of the 16SrRNA gene for the identification and differentiation of mycobacterial species has been recommended [31]. It has been shown to offer several advantages over other target sequences such as the entire 16SrRNA region used in other studies. The 16SrRNA hypervariable region is also more polymorphic than the entire 16SrRNA coding region or portions of the $h s p 65$ gene that has been used in Mycobacterium spp detection, which resulted in an increased discriminatory power in this study. However, this region has also been found to detect other Actinobacteria such as Corynebacteria spp as observed in this and other similar studies [24].

IS2404 is now considered to be non-specific for $M$. ulcerans due to the detection of this insertion sequence in a number of other mycobacterial species such as $M$. liflandii and M. marinum DL [32]. This emphasizes the need for sequencing these targets for accurate species identification. Results from this study suggests the combination of molecular and culturing methods to provide a better characterization of the microbial diversity of chronic wounds. These will help expand our understanding of how microbiology impacts chronic wound pathology and healing.

Several studies have described bacteria that infect lesions as mostly normal skin flora and are therefore, non-pathogenic [33]. Majority of the Staphylococci identified in this study were mannitol fermenters which are considered pathogenic. S. aureus, abundantly found in BU lesions of this study has been found to be the predominant bacteria isolated from several BU wounds $[14,27,28]$. S. aureus have been found to harbor a diverse repertoire of virulence factors such as $\alpha$-hemolysin, and other mobile genetic elements (MGEs) including genomic island prophages and pathogenicity islands [34]. These factors are known promote immune evasion, and development of superantigens which may enhance the persistence and survival of the bacteria in the lesion [34]. Therefore pathogenic Staphylococci may worsen the condition of the ulcers and may delay the healing process of the lesion [35-37].

Gram negative bacteria have been found to be a major contributor of secondary infections in BU lesions [28]. Both gram negative lactose and non-lactose fermenters were isolated from the lesions. Even though $E$. coli is a common microbial infection in BU endemic areas, we did not identify any in the microbial isolates sequenced, nevertheless, Pseudomonas aeruginosa was identified. Lactose negative bacteria which includes $P$. aeruginosa usually cause secondary bacterial infection especially in difficult-to-heal wounds such as skin ulcers [30]. $P$. aeruginosa have been identified to dominate in both pre-treatment and post-treatment of BU [10] and is often cited as a source of delay in wound healing [38, 39]. Klebsiella spp are well known normal flora of the human mouth and the gastrointestinal tract and are scarcely found on the skin[40]. Klebsiella spp and Proteus spp have also been associated with wound infections [41].

Staphylococcus aureus and Alcaligenes spp are usually identified as secondary infections in wounds. Both bacteria have been identified as common nosocomial secondary infections among many of the patients with the disease [42]. In a recent study conducted in Ghana, Staphylococcus spp, which included methicillin resistant $S$. aureus were identified as nosocomial secondary infections among $\mathrm{BU}$ patients with possible transmission from healthcare workers, hospital equipment for wound dressing such as the forceps [13, 43]. Alcaligenes spp have also been recognized as opportunistic emerging infectious gram-negative bacterial species that can affect immunosuppressed patients [44].

Bacillus spp belonging to the $B$. cereus group of bacteria were also identified after sequencing. Bacteria belonging to this group are facultatively anaerobic and spore-forming bacteria. They are known to be frequently distributed in a wide range of environmental niche [45]. Strains from the $B$. cereus group are commonly found as part of the plant and soil microbiome [46]. B. cereus infections of human and domestic animals have also received recognition and increasing number of infections from wounds [47] and insect bites [48] have been reported to have been colonized by these bacteria. It has been noticed mainly in immunosuppressed tissues of wounds [49]. It is therefore, not surprising to be noted as a secondary microorganism in BU wounds.

Due to the similarities between Corynebacterium and Mycobacterium spp, Corynebacterium is sometimes used in the study of Mycobacteria [24, 50]. This could explain why many Corynebacterium spp were noticed after sequencing of the 59 noncoding promoter region of the 16SrRNA gene that targets mycobacteria. These bacteria have been occasionally sequenced using the 16SrRNA primer for Mycobacteria [51]. However, unlike Mycobacteria, Corynebacterium spp are non-acid fast bacteria that can grow on Middlebrook7H9 medium. They are soil dwelling microorganisms that are usually infectious and pathogenic. Some like C. ulcerans can manifest infections on the skin that closely resembles that of $M$. ulcerans [52-54]. Slow healing wounds have been confirmed to be usually colonized by Corynebacterium spp [55]. This could explain why a number of Corynebacterium spp were identified from the microbial isolates. 
Majority of the bacteria identified were pathogenic and opportunistic bacteria that live in muddy areas and in dirty water bodies. Almost all the bacteria are soil dwellers that easily have access to the BU lesion during activities like playing, farming, or mining. Very few were normal body flora that may delay healing of BU lesions.

Fungal elements have been isolated from several ulcers. The most common species identified are Candida, Cryptococcus, Trichosporon and Rhodotorula spp [56]. Thus, fungi identified in this study through staining and culturing was no surprise. Candida duobushaemulonii is part of the Candida haemulonii complex (C. haemulonii, C. haemulonii var. vulnera and C. duobushaemulonii). This group of Candida are noted for their high antifungal resistance, including high minimum inhibitory concentrations (MICs) of amphotericin B and crossresistance to azole compounds [57, 58]. Their presence in the BU lesions may also delay healing. Candida parapsilosis has been described as an opportunistic pathogen. Trichoderma species are common fungal species usually found in humid soil, decaying wood, and water-related sites. T. longibrachiatum, have been identified as causative agents of infections in immunosuppressed hosts [59]. The BU patients may have been infected with the fungi through a variety of sources which may include the farm (a high percentage of the BU study group were farmers), homes and even at the place of treatment such as the hospitals and community treatment centers [13] (Fig. 1). Mycolactone has also been found to enhance spore germination and chemoattractant effects on some fungal species [15]. This may explain the reason for fungal detection in BU lesions as well as the major contaminant for MU culture.

WHO recommends a combination drug of rifampicin and streptomycin or clarithromycin for 8 weeks for the treatment of $\mathrm{BU}$ [60]. Although these have been generally effective in treatment, drugs for secondary microbial infections of BU patients have not yet been recommended. Resistance to streptomycin and rifampicin have been reported for Bacillus spp and the Staphylococcus spp. The Bacillus spp mostly form spores in harsh conditions and this may be the reason for their resistance to the drugs [61]. Streptomycin used for the treatment of secondary $\mathrm{BU}$ infection may be unsuitable due to the high level of resistance of secondary bacteria as observed in a similar study [14]. M. ulcerans is sensitive not just to streptomycin and rifampicin but also to clarithromycin [62-64].

Since all the secondary bacteria identified in this study were susceptible to clarithromycin and amikacin, their continuous use in chemotherapy could serve as treatment for the secondary bacterial infections of BU. The bactericidal activity of the combination rifampicinclarithromycin against $M$. ulcerans has been found to be similar to that of rifampicin-streptomycin [10]. This may likely be a better option for treatment for BU since the secondary bacteria were all susceptible to clarithromycin. To corroborate this observation recent clinical trial in Ghana found rifampicin-clarithromycin combination as a suitable treatment for BU treatment $[63,64]$.

Unfortunately, the long distances to the nearest health center deter most BU patients from seeking treatment. A higher susceptibility was observed among the microorganisms isolated from Buruli ulcer patients who had already began antibiotic treatment (BT) compared to those who had not (BNT). It was also noticed that resistance to the recommended antibiotics, (rifampicin and streptomycin) was higher among the BT compared to the BNT group. High bacterial loads have been found to increase significantly even after treatment of the disease [13]. This could explain the higher level of resistance identified among the BU group who had already began antibiotic treatment. However, other studies, suggest that BU patients with small lesions (category 1) are more likely to heal quicker compared to others if treatment commences early enough [63-65].

The type of secondary microbial infection on a BU patient may not necessarily depend on factors such as geographical area, personal hygiene, type of treatment, among others. In recent studies majority of the secondary bacterial infection in BU patients were like those found in this study $[10,27,28]$. Sequence analysis revealed that majority of the bacteria identified on the BU lesions are Gram positive and negative rods compared to the cocci. Further studies are needed to compare secondary bacterial infection from the surface of BU lesions and from the undermined edges where $M$. ulcerans are predominantly found.

\section{Conclusions}

Secondary microbial infections among BU patients are common; with most being of bacterial etiology. The common bacteria identified are Staphylococcus spp, Bacillus spp, Alcaligenes spp and Pseudomonas spp. Predominant bacteria present among both BU and NonBU patients were found to be Staphylococcus spp and Bacillus spp. Fungal species identified were mainly Candida spp. The selected bacteria were all susceptible to amikacin and clarithromycin, however, high resistance was observed with streptomycin. These microbial infections may delay healing and increase resistance to antibiotics administered to BU patients.

The attitude of patients to BU may also lead to secondary microbial infections on the lesions. Most patients report very late for treatment. Some even worsen the lesion using non-aseptic herbal medications, which are additional source of secondary microbial infections. Although risk factors for bacterial wound colonization have 
not been thoroughly studied to date, delayed treatment and insufficient wound management might contribute to colonization and prolonged wound healing. There is thus, the need to seek medical help as soon as possible when signs of BU are noticed. Home dressing and traditional healing should be discouraged if possible. Since many of the bacteria identified are soil dwellers, BU patients should be educated on the importance of personal hygiene and the wearing of protective clothing when attending to their various occupations to prevent the proliferation of these secondary microorganisms.

\section{Methods}

\section{Study design}

This study was cross-sectional and designed to identify secondary microorganism from suspected BU lesions within a period of 2 years, from June 2014 to June 2016.

\section{Study communities}

An active case search for suspected and unreported BU cases was conducted in all the study communities in the Amansie Central District of the Ashanti Region, Ghana. Suspected BU cases [15] who reported to the St. Peter's hospital and had had their cases confirmed with acid fast staining but not IS2404 (the gold standard for BU confirmation) were included in this study. In all, a total of fifty-one [55] suspected BU cases were identified in the district. The 51 participants all consented to the study and were recruited from $25 \mathrm{BU}$ endemic communities, with majority from Jacobu (56\%), Krofrom (20\%), Homase (16 $\mathrm{mm} \%)$ and Donkoase (12\%). A questionnaire was administered to each participant to gather basic demographic information including age, residence, occupation, treatment status and category of lesion. Majority of the inhabitants in the Amansie Central district are farmers, with some inhabitants involved in small-scale surface gold mining (galamsey) along the rivers which run through the district. At least one functioning borehole was found in each community. Nevertheless, the inhabitants still fetched water from the river for domestic and agricultural activities [24].

\section{Sample collection}

Multiple swabs [3] were taken from all suspected BU cases having clinical presentation of BU (from the undermined edges of open lesions and from the surface of the lesion) and were placed in labeled sterile $15 \mathrm{~mL}$ sterile falcon tubes. The samples were preserved with ice packs in a cooler and transported to the St. Peters Hospital (Jacobu) for temporal storage at $4^{\circ} \mathrm{C}$ and onward transport in cold storage to the laboratory at the Department of Biochemistry, Cell and Molecular Biology in Accra.

\section{Sample processing for laboratory analyses}

The swabs were processed for microscopy, culture and DNA extraction. Briefly, $2 \mathrm{~mL}$ of $1 \mathrm{X}$ Phosphate Buffer Saline (PBS) was added to the $15 \mathrm{~mL}$ falcon tube containing the swab and the tube was vortexed for 5 minutes to dislodge microbial cells from the swabs. The mixture was then used for acid-fast staining $(10 \mu \mathrm{L})$, culturing $(10 \mu \mathrm{L})$ and DNA extraction $(200 \mu \mathrm{L})$. The remaining mixture was preserved at $4^{\circ} \mathrm{C}$ for later use.

\section{BU case confirmation}

To detect $M$. ulcerans infections, acid-fast staining was performed on samples stored in PBS, following the protocol from BD Biosciences. This was then followed by PCR confirmation. Briefly, genomic DNA was extracted from $200 \mu \mathrm{L}$ of the PBS mixture using the Zymogene Quick-DNA ${ }^{\mathrm{TM}}$ Miniprep Kit. The purified genomic DNA was then used for PCR targeting the IS2404 sequence. This insertion sequence is the WHO recommended molecular diagnostic marker for BU case confirmation and is present in over 200 copies on the genome of mycolactone producing mycobacteria [20]. Patients with confirmed M. ulcerans infection, i.e. BU, were referred to their respective Community Health Centers for treatment.

\section{Culture isolation of secondary microorganisms}

To isolate secondary microorganisms from the lesions, the samples stored in PBS were cultured on each of the following media : Luria Bertani (LB) agar at $37^{\circ} \mathrm{C}$ (for the isolation of general bacteria), MacConkey agar at $37^{\circ} \mathrm{C}$ (for the isolation of Gram negative and enteric bacteria), Mannitol salt agar at $37^{\circ} \mathrm{C}$ (for the isolation of Staphylococci and micrococci bacteria), Sabouraud dextrose agar supplemented with chloramphenicol at $30^{\circ} \mathrm{C}$ (for the isolation of fungal elements) and Middlebrook $7 \mathrm{H} 10$ agar at $32^{\circ} \mathrm{C}$ (for the isolation of Mycobacterium spp). All bacteria were cultured for 16 to 24 hours, 5 days to 1 week for fungal growth and up to 6 months for mycobacteria. All bacterial growth observed were either Gram or acid-fast stained to confirm type of bacteria. All fungal species were also observed under a microscope using the wet mount technique.

\section{Molecular identification of microorganisms}

To identify the cultured bacterial isolates, we amplified and sequenced the 16SrRNA using previously published primers including the universal bacteria [22], and Mycobacterium-specific 16SrRNA primers [23]. To distinguish the mycolactone producing mycobacteria (MPM) from other mycobacteria we amplified and sequenced the IS2404 gene as described previously [24, 25]. To identify infecting fungi, we amplified and sequenced the Internal transcribed Spacer region (ITS) as described 
elsewhere [26]. All primers used are described in Table 1. All PCR amplicons were Sanger-sequenced (Macrogen Inc, Netherlands) and quality filtering was done by trimming the ends of the nucleotide sequence using Finch TV chromatogram viewer (version 1.4.0). The sequence reads were queried using the BLASTn program on NCBI (https://blast.ncbi.nlm.nih.gov/Blast.cgi). The E-value for homology comparison among the species was chosen to be below $10^{-4}$ or 0.0001 . Search queries with first hits $>90 \%$ nucleotide similarity was used to characterize isolates [66].

\section{Antibiotic susceptibility testing}

Following the molecular identification of the bacterial isolates, we performed drug sensitivity testing to assess their susceptibility to the commonly used anti-mycobacterial drug on Mueller Hinton agar plate and incubated at $37^{\circ} \mathrm{C}$ for 18 hours. The antibiotic used were amikacin $(30 \mu \mathrm{g})$, kanamycin $(30 \mu \mathrm{g})$, clarithromycin $(30 \mu \mathrm{g})$, hygromycin B $(30 \mu \mathrm{g})$, streptomycin $(10 \mu \mathrm{g})$ and rifampicin $(5 \mu \mathrm{g})$. These tests were performed using the Kirby Bauer protocol [67].

\begin{abstract}
Abbreviations
BU: Buruli ulcer; MPM: Mycolactone Producing Mycobacteria; PBS: Phosphate Buffer Saline; NCBI: National Center for Biotechnology Information; IS2404: Insertion Sequence 2404; spp: Species; CLR: Clarithromycin; HMB: Hygromycin; AMK: Amikacin; KAN: Kanamycin; SPT: Streptomycin; RIF: Rifampicin; BNT: Buruli ulcer cases not under treatment; BT: Buruli ulcer cases under treatment
\end{abstract}

\section{Acknowledgements}

We thank all the study participants, District Health Directorate and staff of St. Peter's Hospital, Jacobu. We also thank Mr. Kweku Donkor, Gideon Senyo Amevinya, Godwin Williams Amatsi, Sandra Sowah, Georgia Ghartey for their laboratory assistance as well as Mr. David Abana (Ghana Food and Drugs Authority) for some reagents.

\section{Authors' contributions}

$L M, C Q$ and $C N$ designed and supervised the study and reviewed the manuscript for intellectual content. EG conducted the laboratory and data analysis and drafted the manuscript. AA participated in the laboratory analysis. BD reviewed the manuscript for intellectual content. All authors read and approved the final version of the manuscript.

\section{Funding}

This work was funded by the University of Ghana Research Fund (URF/6/LG008/2012-2013). The funding body has no role in the design of the study, collection, analysis, interpretation of data and in writing the manuscript.

\section{Availability of data and materials}

All data generated or analyzed during this study are included in this published article and its supplementary information files.

\section{Ethics approval and consent to participate}

This study was approved by the Ethical and Protocol Review Committee of the University of Ghana Medical School [MS-ET/M.11 - P 3.1/2013-2014]. In addition, permission and approval was sought from the District Health Directorate and the traditional leaders of the respective communities before we commenced field studies. All participants signed a written informed consent form before recruitment into the study. Parents and guardians consented for their children below 18 years before they were enrolled into the study. All suspected cases were confirmed by PCR and patients who were positive for $\mathrm{MU}$ were later referred to their respective Community Health Centers for treatment.

\section{Consent for publication}

All participant consent to publication provided their names and images were not disclosed.

\section{Competing interests}

The authors declare that they have no competing interest.

\section{Author details}

'Department of Medical Biochemistry, University of Ghana Medical School, Korle Bu, Accra, Ghana. ${ }^{2}$ Department of Biochemistry, Cell and Molecular Biology, University of Ghana, Legon, Accra, Ghana. ${ }^{3}$ West African Center for Cell Biology of Infectious Pathogens, University of Ghana, Legon, Accra, Ghana. ${ }^{4}$ Noguchi Memorial Institute for Medical Research, University of Ghana, Legon, Accra, Ghana. ${ }^{5}$ Burnet Institute for Medical Research, Melbourne, Australia.

Received: 19 June 2020 Accepted: 15 December 2020

Published online: 05 January 2021

\section{References}

1. Walsh DS, Eyase F, Onyango D, Odindo A, Otieno W, Waitumbi JN, et al. Short report: Clinical and molecular evidence for a case of Buruli ulcer (Mycobacterium ulcerans infection) in Kenya. Am J Trop Med Hyg. 2009; 81(6):1110-3.

2. Johnson PD, Stinear T, Small PL, Pluschke G, Merritt RW, Portaels F, et al. Buruli ulcer (M. ulcerans infection): new insights, new hope for disease control. PLoS Med. 2005;2(4):e108.

3. Duker AA, Carranza EJ, Hale M. Spatial dependency of Buruli ulcer prevalence on arsenic-enriched domains in Amansie West District, Ghana: implications for arsenic mediation in Mycobacterium ulcerans infection. Int J Health Geogr. 2004;3(1):19.

4. Stinear TP, Mve-Obiang A, Small PL, Frigui W, Pryor MJ, Brosch R, et al. Giant plasmid-encoded polyketide synthases produce the macrolide toxin of Mycobacterium ulcerans. Proc Natl Acad Sci U S A. 2004;101(5):1345-9.

5. Hong H, Demangel C, Pidot SJ, Leadlay PF, Stinear T. Mycolactones: immunosuppressive and cytotoxic polyketides produced by aquatic mycobacteria. Nat Prod Rep. 2008;25(3):447-54.

6. Woolley RJ, Velink A, Phillips RO, Thompson WA, Abass KM, van der Werf TS, et al. Experiences of Pain and Expectations for Its Treatment Among Former Buruli Ulcer Patients. Am J Trop Med Hyg. 2016;95(5):1011-5.

7. de Zeeuw J, Alferink M, Barogui YT, Sopoh G, Phillips RO, van der Werf TS, et al. Assessment and Treatment of Pain during Treatment of Buruli Ulcer. PLoS Negl Trop Dis. 2015;9(9):e0004076.

8. Phillips R, Sarfo FS, Guenin-Mace L, Decalf J, Wansbrough-Jones M, Albert $\mathrm{ML}$, et al. Immunosuppressive signature of cutaneous Mycobacterium ulcerans infection in the peripheral blood of patients with buruli ulcer disease. J Infect Dis. 2009;200(11):1675-84.

9. Silva MT, Portaels F, Pedrosa J. Pathogenetic mechanisms of the intracellular parasite Mycobacterium ulcerans leading to Buruli ulcer. Lancet Infect Dis. 2009;9(11):699-710.

10. Yeboah-Manu D, Kpeli GS, Ruf MT, Asan-Ampah K, Quenin-Fosu K, OwusuMireku E, et al. Secondary bacterial infections of buruli ulcer lesions before and after chemotherapy with streptomycin and rifampicin. PLoS Negl Trop Dis. 2013;7(5):e2191.

11. Van Leuvenhaege C, Vandelannoote K, Affolabi D, Portaels F, Sopoh G, de Jong $B C$, et al. Bacterial diversity in Buruli ulcer skin lesions: Challenges in the clinical microbiome analysis of a skin disease. PLoS One. 2017;12(7): e0181994.

12. Toutous Trellu L, Nkemenang P, Mboua B, Tschanz E, Ehounou G, Comte E, et al. [Differential diagnoses of infection with Mycobacterium ulcerans: case reports from Akonolinga, Cameroon]. Med Sante Trop. 2013;23(2):229.

13. Kpeli G, Darko Otchere I, Lamelas A, Buultjens AL, Bulach D, Baines SL, et al. Possible healthcare-associated transmission as a cause of secondary infection and population structure of Staphylococcus aureus isolates from two wound treatment centres in Ghana. New Microbes New Infect. 2016;13:92-101. 
14. Kpeli GS, Yeboah-Manu D. Secondary Infection of Buruli Ulcer Lesions. In: Pluschke G, Roltgen K, editors Buruli Ulcer: Mycobacterium ulcerans Disease Cham (CH)2019. p. 227-39.

15. Hammoudi N, Cassagne C, Armstrong N, Ranque S, Henrissat B, Drancourt $\mathrm{M}$, et al. Mycobacterium ulcerans mycolactones-fungi crosstalking. Sci Rep. 2019;9(1):3028

16. Sibbald RG, Orsted $H$, Schultz GS, Coutts P, Keast D, International Wound Bed Preparation Advisory B, et al. Preparing the wound bed 2003: focus on infection and inflammation. Ostomy Wound Manage. 2003;49(11):24-51.

17. Erol S, Altoparlak U, Akcay MN, Celebi F, Parlak M. Changes of microbial flora and wound colonization in burned patients. Burns. 2004;30(4):357-61.

18. Katz T, Wasiak J, Cleland H, Padiglione A. Incidence of non-candidal fungal infections in severe burn injury: an Australian perspective. Burns. 2014;40(5): $881-6$.

19. Barogui YT, Klis S, Bankole HS, Sopoh GE, Mamo S, Baba-Moussa L, et al. Towards rational use of antibiotics for suspected secondary infections in Buruli ulcer patients. PLoS Negl Trop Dis. 2013;7(1):e2010.

20. Buruli ulcer- diagnosis of Mycobacterium ulcerans disease. 2016. Available from: https://www.who.int/news-room/fact-sheets/detail/buruli-ulcer(mycobacterium-ulcerans-infection).

21. Sakyi SA, Aboagye SY, Darko Otchere I, Yeboah-Manu D. Clinical and Laboratory Diagnosis of Buruli Ulcer Disease: A Systematic Review. Can J Infect Dis Med Microbiol. 2016;2016:5310718.

22. Reysenbach AL, Ehringer M, Hershberger K. Microbial diversity at 83 degrees $C$ in Calcite Springs, Yellowstone National Park: another environment where the Aquificales and "Korarchaeota" coexist. Extremophiles. 2000;4(1):61-7.

23. Hughes MS, Skuce RA, Beck LA, Neill SD. Identification of mycobacteria from animals by restriction enzyme analysis and direct DNA cycle sequencing of polymerase chain reaction-amplified 165 rRNA gene sequences. J Clin Microbiol. 1993;31(12):3216-22.

24. Narh CA, Mosi L, Quaye C, Dassi C, Konan DO, Tay SC, et al. Source tracking Mycobacterium ulcerans infections in the Ashanti region, Ghana. PLoS Negl Trop Dis. 2015;9(1):e0003437.

25. Ablordey A, Amissah DA, Aboagye IF, Hatano B, Yamazaki T, Sata T, et al. Detection of Mycobacterium ulcerans by the loop mediated isothermal amplification method. PLoS Negl Trop Dis. 2012;6(4):e1590.

26. Cendejas-Bueno E, Gomez-Lopez A, Mellado E, Rodriguez-Tudela JL, Cuenca-Estrella M. Identification of pathogenic rare yeast species in clinical samples: comparison between phenotypical and molecular methods. J Clin Microbiol. 2010;48(5):1895-9.

27. Amissah NA, Glasner C, Ablordey A, Tetteh CS, Kotey NK, Prah I, et al. Genetic diversity of Staphylococcus aureus in Buruli ulcer. PLoS Negl Trop Dis. 2015;9(2):e0003421.

28. Anyim MC, Meka AO, Chukwu JN, Nwafor CC, Oshi DC, Madichie NO, et al. Secondary bacterial isolates from previously untreated Buruli ulcer lesions and their antibiotic susceptibility patterns in Southern Nigeria. Rev Soc Bras Med Trop. 2016:49(6):746-51.

29. Guimaraes-Peres A, Portaels F, de Rijk P, Fissette K, Pattyn SR, van Vooren J, et al. Comparison of two PCRs for detection of Mycobacterium ulcerans. J Clin Microbiol. 1999;37(1):206-8.

30. Sienkiewicz M, Poznanska-Kurowska K, Kaszuba A, Kowalczyk E. The antibacterial activity of geranium oil against Gram-negative bacteria isolated from difficult-to-heal wounds. Burns. 2014;40(5):1046-51.

31. Chakravorty S, Helb D, Burday M, Connell N, Alland D. A detailed analysis of 165 ribosomal RNA gene segments for the diagnosis of pathogenic bacteria. J Microbiol Methods. 2007;69(2):330-9.

32. Yip MJ, Porter JL, Fyfe JA, Lavender CJ, Portaels F, Rhodes M, et al. Evolution of Mycobacterium ulcerans and other mycolactone-producing mycobacteria from a common Mycobacterium marinum progenitor. J Bacteriol. 2007; 189(5):2021-9.

33. Davis CP. Normal Flora. In: Baron th $\mathrm{S}$, editors. Medical Microbiology. Galveston (TX)1996.

34. Amissah NA, Chlebowicz MA, Ablordey A, Tetteh CS, Prah I, van der Werf TS et al. Virulence potential of Staphylococcus aureus isolates from Buruli ulcer patients. Int J Med Microbiol. 2017;307(4-5):223-32.

35. Pastar I, Nusbaum AG, Gil J, Patel SB, Chen J, Valdes J, et al. Interactions of methicillin resistant Staphylococcus aureus USA300 and Pseudomonas aeruginosa in polymicrobial wound infection. PLoS One. 2013;8(2):e56846.

36. Serra R, Grande R, Butrico L, Rossi A, Settimio UF, Caroleo B, et al. Chronic wound infections: the role of Pseudomonas aeruginosa and Staphylococcus aureus. Expert Rev Anti Infect Ther. 2015;13(5):605-13.
37. Schierle CF, De la Garza M, Mustoe TA, Galiano RD. Staphylococcal biofilms impair wound healing by delaying reepithelialization in a murine cutaneous wound model. Wound Repair Regen. 2009;17(3):354-9.

38. Danielsen L, Balslev E, Doring G, Hoiby N, Madsen SM, Agren M, et al. Ulcer bed infection. Report of a case of enlarging venous leg ulcer colonized by Pseudomonas aeruginosa. APMIS. 1998;106(7):721-6.

39. Twum-Danso K, Grant C, al-Suleiman SA, Abdel-Khader S, al-Awami MS, alBreiki $\mathrm{H}$, et al. Microbiology of postoperative wound infection: a prospective study of 1770 wounds. J Hosp Infect. 1992;21(1):29-37.

40. Lin AC, Liao TL, Lin YC, Lai YC, Lu MC, Chen YT. Complete genome sequence of Klebsiella pneumoniae 1084, a hypermucoviscosity-negative K1 clinical strain. J Bacteriol. 2012;194(22):6316.

41. Shrestha B, Marhatha R, Giri A, Jaisi S, Maskey U. Surgical site wound infection in relation to antibiotic prophylaxis given before skin incision and after cord clamping during cesarean delivery. Nepal Med Coll J. 2014;16(24):148-51.

42. Aisenberg G, Rolston KV, Safdar A. Bacteremia caused by Achromobacter and Alcaligenes species in 46 patients with cancer (1989-2003). Cancer. 2004;101(9):2134-40.

43. Kpeli G, Buultjens AH, Giulieri S, Owusu-Mireku E, Aboagye SY, Baines SL, et al. Genomic analysis of ST88 community-acquired methicillin resistant Staphylococcus aureus in Ghana. PeerJ. 2017;5:e3047.

44. Rasko DA, Altherr MR, Han CS, Ravel J. Genomics of the Bacillus cereus group of organisms. FEMS Microbiol Rev. 2005;29(2):303-29.

45. Luna VA, King DS, Gulledge J, Cannons AC, Amuso PT, Cattani J. Susceptibility of Bacillus anthracis, Bacillus cereus, Bacillus mycoides, Bacillus pseudomycoides and Bacillus thuringiensis to 24 antimicrobials using Sensititre automated microbroth dilution and Etest agar gradient diffusion methods. J Antimicrob Chemother. 2007;60(3):555-67.

46. Kotiranta A, Lounatmaa K, Haapasalo M. Epidemiology and pathogenesis of Bacillus cereus infections. Microbes Infect. 2000;2(2):189-98.

47. Ehling-Schulz M, Lereclus D, Koehler TM. The Bacillus cereus Group: Bacillus Species with Pathogenic Potential. Microbiol Spectr. 2019;7(3).

48. Bottone EJ. Bacillus cereus, a volatile human pathogen. Clin Microbiol Rev. 2010;23(2):382-98.

49. Harper C, Hayward D, Wiid I, van Helden P. Regulation of nitrogen metabolism in Mycobacterium tuberculosis: a comparison with mechanisms in Corynebacterium glutamicum and Streptomyces coelicolor. IUBMB Life. 2008;60(10):643-50.

50. Narh CA, Mosi L, Quaye C, Tay SC, Bonfoh B, de Souza DK. Genotyping Tools for Mycobacterium ulcerans-Drawbacks and Future Prospects. Mycobact Dis. 2014;4(2):1000149.

51. Werdin F, Tennenhaus M, Schaller HE, Rennekampff HO. Evidence-based management strategies for treatment of chronic wounds. Eplasty. 2009;9:e19.

52. Corti MA, Bloemberg GV, Borelli S, Kutzner H, Eich G, Hoelzle L, et al. Rare human skin infection with Corynebacterium ulcerans: transmission by a domestic cat. Infection. 2012:40(5):575-8.

53. Wagner J, Ignatius R, Voss S, Hopfner V, Ehlers S, Funke G, et al. Infection of the skin caused by Corynebacterium ulcerans and mimicking classical cutaneous diphtheria. Clin Infect Dis. 2001;33(9):1598-600.

54. Sing A, Hogardt $M$, Bierschenk $S$, Heesemann J. Detection of differences in the nucleotide and amino acid sequences of diphtheria toxin from Corynebacterium diphtheriae and Corynebacterium ulcerans causing extrapharyngeal infections. J Clin Microbiol. 2003;41(10):4848-51.

55. Silva CM, Carvalho-Parahym AM, Macedo DP, Lima-Neto RG, Francisco EC, Melo AS, et al. Neonatal Candidemia Caused by Candida haemulonii: Case Report and Review of Literature. Mycopathologia. 2015;180(1-2):69-73.

56. Wisplinghoff $H$, Bischoff $T$, Tallent SM, Seifert $H$, Wenzel RP, Edmond MB. Nosocomial bloodstream infections in US hospitals: analysis of 24,179 cases from a prospective nationwide surveillance study. Clin Infect Dis. 2004;39(3): 309-17.

57. Zhang $\mathrm{S}, \mathrm{Xu} B$, Xue Y, Liu J. Parasitic and lethal action of Trichoderma longibrachiatum against Heterodera avenae. Wei Sheng Wu Xue Bao. 2014; 54(7):793-802

58. Almeida Junior JN, Song AT, Campos SV, Strabelli TM, Del Negro GM, Figueiredo DS, et al. Invasive Trichosporon infection in solid organ transplant patients: a report of two cases identified using IGS1 ribosomal DNA sequencing and a review of the literature. Transpl Infect Dis. 2014; 16(1):135-40.

59. Missoni EM, Kalenic S, Vukelic M, De Syo D, Belicza M, Kern J, et al. Role of yeasts in diabetic foot ulcer infection. Acta Med Croatica. 2006;60(1):43-50. 
60. Yotsu RR, Suzuki K, Simmonds RE, Bedimo R, Ablordey A, Yeboah-Manu D, et al. Buruli Ulcer: a Review of the Current Knowledge. Curr Trop Med Rep. 2018;5(4):247-56.

61. Thwaite JE, Laws TR, Atkins TP, Atkins HS. Differential cell surface properties of vegetative Bacillus. Lett Appl Microbiol. 2009;48(3):373-8.

62. Ji B, Chauffour A, Robert J, Lefrancois S, Jarlier V. Orally administered combined regimens for treatment of Mycobacterium ulcerans infection in mice. Antimicrob Agents Chemother. 2007;51(10):3737-9.

63. Phillips RO, Robert J, Abass KM, Thompson W, Sarfo FS, Wilson T, et al. Rifampicin and clarithromycin (extended release) versus rifampicin and streptomycin for limited Buruli ulcer lesions: a randomised, open-label, noninferiority phase 3 trial. Lancet. 2020;395(10232):1259-67.

64. Phillips RO, Sarfo FS, Abass MK, Abotsi J, Wilson T, Forson M, et al. Clinical and bacteriological efficacy of rifampin-streptomycin combination for two weeks followed by rifampin and clarithromycin for six weeks for treatment of Mycobacterium ulcerans disease. Antimicrob Agents Chemother. 2014; 58(2):1161-6.

65. Nienhuis WA, Stienstra Y, Thompson WA, Awuah PC, Abass KM, Tuah W, et al. Antimicrobial treatment for early, limited Mycobacterium ulcerans infection: a randomised controlled trial. Lancet. 2010;375(9715):664-72.

66. Tano MB, Dassi C, Mosi L, Koussemon M, Bonfoh B. Molecular Characterization of Mycolactone Producing Mycobacteria from Aquatic Environments in Buruli Ulcer Non-Endemic Areas in Cote d'Ivoire. Int J Environ Res Public Health. 2017;14(2)

67. Bauer AW, Kirby WM, Sherris JC, Turck M. Antibiotic susceptibility testing by a s tandardized single disk method. Am J Clin Pathol. 1966;45(4):493-6.

\section{Publisher's Note}

Springer Nature remains neutral with regard to jurisdictional claims in published maps and institutional affiliations.

Ready to submit your research? Choose BMC and benefit from:

- fast, convenient online submission

- thorough peer review by experienced researchers in your field

- rapid publication on acceptance

- support for research data, including large and complex data types

- gold Open Access which fosters wider collaboration and increased citations

- maximum visibility for your research: over $100 \mathrm{M}$ website views per year

At $\mathrm{BMC}$, research is always in progress.

Learn more biomedcentral.com/submissions 